Revue de droit comparé du travail et de la sécurité sociale

3 | 2020

La Directive 2019/1158 du 20 juin 2019 concernant l'équilibre entre vie personnelle et vie privée des parents et des aidants

\title{
Le travail à distance, mesure de prévention face à la propagation du Covid 19
}

\section{Maria Katia Garcia Landaburu}

\section{(2) OpenEdition \\ Journals}

Édition électronique

URL : https://journals.openedition.org/rdctss/1029

DOI : $10.4000 /$ rdctss. 1029

ISSN : 2262-9815

Éditeur

Centre de droit comparé du travail et de la sécurité sociale

Édition imprimée

Date de publication : 1 novembre 2020

Pagination : 180-183

ISSN : 2117-4350

Référence électronique

Maria Katia Garcia Landaburu, « Le travail à distance, mesure de prévention face à la propagation du Covid 19 », Revue de droit comparé du travail et de la sécurité sociale [En ligne], 3 | 2020, mis en ligne le 01 novembre 2021, consulté le 11 novembre 2021. URL : http://journals.openedition.org/rdctss/1029 ; DOI : https://doi.org/10.4000/rdctss.1029

\section{(c) $(1)$}

Revue de droit comparé du travail et de la sécurité sociale est mise à disposition selon les termes de la Licence Creative Commons Attribution - Pas d'Utilisation Commerciale - Pas de Modification 4.0 International. 


\title{
MARÍA KATIA GARCÍA LANDABURU
}

\author{
Université PONTIFICALE CATHOLIQUE du PÉrou
}

\section{LE TRAVAIL À DISTANCE, MESURE DE PRÉVENTION FACE À LA PROPAGATION DU COVID 19}

Comme de nombreux pays, le Pérou a pris diverses mesures pour protéger sa population contre la pandémie. À partir du 15 mars dernier, une fois l'état d'urgence national déclaré par le Décret Suprême (D.S.) 044-2020-PCM, des dispositions spécifiques ont été mises en place dans le domaine du travail. La liberté de mouvement a été réduite : seuls les déplacements de personnes liés à la fourniture de services et de biens essentiels, tels que l'acquisition, la production et la distribution de produits alimentaires et pharmaceutiques, étaient autorisés. De nombreux travailleurs se sont retrouvés ainsi dans l'impossibilité de poursuivre leur activité sur leur lieu de travail. Parallèlement à la déclaration de l'état d'urgence nationale, le Décret d'Urgence (D.U.) 026-2020 a énoncé plusieurs mesures exceptionnelles et temporaires destinées à prévenir la propagation du virus. Parmi elles, figure la mise en place du travail à distance (II), précisé quelques jours plus tard par le D.S. 010-2020-TR. Cette nouvelle modalité de prestation de services récemment approuvée par le D.S 009-2015-TR, présente des caractéristiques particulières, différentes de celles du télétravail (I) qui est réglementé au Pérou depuis 2013 par la loi n³0036.

\section{I - LE TÉLÉTRAVAIL AU PÉROU}

La législation péruvienne a défini le télétravail comme une modalité spéciale de prestation de services, caractérisée par l'utilisation des technologies de l'information et de la communication. Il se caractérise par l'exécution subordonnée de tâches sans la présence physique du travailleur au sein de l'entreprise avec laquelle il a une relation de travail. Les tâches sont réalisées par le biais de l'informatique, des télécommunications et de moyens analogues, permettant également le contrôle et la supervision du travail effectué.

Le télétravail présente deux caractéristiques principales :

- Il est basé sur le volontariat (et ne peut donc pas être imposé par l'employeur).

- L'employeur doit fournir les équipements et autres matériels nécessaires, ou le cas échéant en assumer le coût.

En ce qui concerne le caractère volontaire du télétravail, la décision se fait au début de la relation de travail, ou ultérieurement lorsque le passage au télétravail est proposé, soit de manière permanente, soit pour une période déterminée. Les parties sont alors tenues de signer un document contenant au minimum des informations sur :

- les moyens informatiques, de télécommunications et autres devant être utilisés, ainsi que les responsabilités incombant au télétravailleur si ces moyens sont mis à disposition par l'employeur, ou le montant de l'indemnisation s'ils sont fournis par le télétravailleur;

- les mesures relatives à la gestion et à la sécurité des informations ;

- les horaires de travail ; 
- le mécanisme de supervision ou de compte rendu du travail effectué pour - faciliter le contrôle et le suivi des tâches réalisées ;

- en cas de passage d'une organisation de travail classique à un télétravail, les motifs et les objectifs de ce changement.

La fin du télétravail intervient à l'expiration du délai convenu, ou d'un commun accord entre les parties. Si la décision est prise de façon unilatérale par l'employeur, celui-ci doit apporter la preuve que le recours au télétravail n'a pas permis d'atteindre les objectifs fixés. L'employeur doit préciser ces objectifs au travailleur, qui a le droit de contester la décision. Le télétravailleur peut, lui aussi, demander l'arrêt du télétravail. Dans ce cas, l'employeur pourra alors s'y opposer en faisant usage de son pouvoir de direction, mais il devra motiver sa décision.

Par ailleurs, le télétravail impose à l'employeur de fournir l'équipement et le matériel nécessaires, ou d'indemniser le travailleur s'ils sont fournis par ce dernier. Cette compensation doit être financière et versée dans une monnaie ayant cours légal, le montant étant fixé d'un commun accord entre les parties (en l'absence d'accord, la valeur marchande sera retenue).

Aucune disposition expresse n'a été prévue s'agissant du droit à la déconnexion, mais il est souligné que des efforts doivent être faits pour concilier vie personnelle, vie familiale et vie professionnelle, et veiller à l'équilibre de ces trois sphères.

Le télétravail est peu utilisé au Pérou. En décembre 2019, les statistiques du ministère du Travail et de la promotion de l'Emploi (MTPE) faisaient état de 2116 télétravailleurs, parmi lesquels 762 étaient en télétravail complet et 1354 en télétravail mixte, c'est-àdire en alternance avec du présentiel sur le lieu de travail. II est impossible de connaître avec certitude les raisons pour lesquelles cette modalité de travail n'attire que peu les employeurs, mais on peut supposer que la crainte de perdre le contrôle direct du travailleur, et les coûts de mise en œuvre du télétravail, sont des facteurs non négligeables aux yeux des entreprises.

La situation a évolué cette année, en raison du confinement obligatoire (quarantaine), strictement appliqué au Pérou depuis le 16 mars, et l'arrêt quasi-total de l'économie. Lorsque les premières mesures contre la propagation du virus ont été énoncées, le MTPE a approuvé un guide qui présentait le télétravail comme l'une des options pouvant être mises en œuvre. Mais lorsque l'état d'urgence nationale a été déclaré, le gouvernement a opté pour une nouvelle modalité de travail, extraordinaire et temporaire (en principe, ne pouvant être appliquée que pendant l'urgence sanitaire) : le travail à distance.

\section{II - LE TRAVAIL À DISTANCE}

Le travail à distance a été défini comme la prestation de services réalisée par un travailleur physiquement présent à son domicile ou sur son lieu d'isolement, ayant recours à tout moyen ou mécanisme permettant d'exercer ses fonctions en dehors du lieu de travail, dans la mesure où la nature de l'activité le permet. II ne se limite pas aux tâches pouvant être effectuées par ordinateur, télécommunications ou autres moyens similaires, mais s'étend à tout type de prestation ne nécessitant pas la présence physique du travailleur sur son lieu de travail. Autrement dit, son champ d'application est plus large que celui du télétravail. II partage avec celui-ci la dimension topographique (prestation réalisée en dehors du lieu de travail), mais sans que la dimension technologique soit indispensable, le travail à distance 
pouvant être effectué par tout moyen ou mécanisme, dans la mesure où la nature du travail le permet. Toutefois, dans la plupart des cas, les activités permettant le plus aisément la mise en place du travail à distance sont celles où la composante technologique existe.

Le travail à distance présente les caractéristiques suivantes :

- L'employeur peut décider de le mettre en place (A), en informant le travailleur (aucun accord des parties n'est requis).

- Les équipements et moyens de toute nature, nécessaires à la prestation de services peuvent être fournis par l'employeur ou le travailleur (B).

Comme on peut le constater, ces caractéristiques diffèrent de celles du télétravail, étant donné la situation d'urgence ayant mené à son adoption.

\section{A - LA MISE EN PLACE du tRAVAIL À DISTANCE}

En ce qui concerne la première caractéristique, il a été établi qu'il suffisait d'informer le travailleur du changement de lieu de la prestation de services, par le biais d'un support physique ou numérique (courrier électronique, intranet, extranet, applications de messagerie instantanée, réseaux sociaux ou autres) qui permette d'enregistrer la communication individuelle, en indiquant:

- la durée ;

- les moyens ou mécanismes nécessaires au travail à distance et la partie tenue de les mettre en place ;

- les conditions applicables en matière de santé et de sécurité au travail, en précisant le biais par lequel le travailleur peut communiquer les risques particuliers qu'il identifie ou les accidents du travail ;

- les autres aspects liés à la prestation de services.

Bien qu'en principe la décision du travail à distance revient à l'employeur (à quelques exceptions près), celui-ci n'a pas vraiment le choix, à moins que l'activité exercée puisse être poursuivie. L'autre option prévue par le gouvernement était l'octroi d'un congé payé sous réserve d'une compensation ultérieure, impliquant pour l'employeur de continuer à verser une rémunération sans nécessairement pouvoir générer de revenus pendant cette période, en cumulant les heures déjà payées, pour les compenser par un travail futur.

Depuis le 13 avril dernier seulement, si la mise en place du travail à distance ou d'un congé payé s'avère impossible en raison de la nature des activités ou du niveau du préjudice économique, le D.U. 038-2020 autorise l'adoption d'autres mesures. Celles-ci doivent avoir pour objectif de maintenir le lien de travail et de garantir le versement de la rémunération au travailleur. La recherche d'un commun accord avec ce dernier doit toujours être privilégiée et, exceptionnellement, si aucun accord n'est possible, la « suspension parfaite » du travail (sans rémunération) est autorisée, après en avoir informé le MTPE qui en vérifiera la légitimité.

Comme indiqué précédemment, il existe des situations dans lesquelles la mise en place du travail à distance ne constitue pas toujours une prérogative unilatérale de l'employeur : - Les travailleurs considérés comme faisant partie du groupe à risque en raison de leur âge (65 ans ou plus) ou de facteurs cliniques déterminés par le ministère de la Santé. Pour ceux-là, le travail à distance est obligatoire pendant toute la durée de l'urgence sanitaire, 
sauf si la nature du travail réalisé est incompatible avec le travail à distance, auquel cas l'employeur doit accorder un congé payé sous réserve d'une indemnisation ultérieure. Depuis le mois de mai, si ces personnes souhaitent participer aux activités autorisées, le D.S. 083-2020-PCM leur permet de signer sous serment une déclaration de prise en charge volontaire, conformément aux dispositions émises par le MTPE.

- Les travailleurs handicapés, ou ceux qui ont à leur charge un membre de leur famille (jusqu'au quatrième degré de consanguinité ou au deuxième degré d'affinité) diagnostiqué positif au COVID-19, ou une personne handicapée appartenant à un groupe à risque. Ils pourront travailler à distance si leurs missions sont compatibles avec cette modalité de travail. Dans le cas contraire, ou en l'absence d'accord, il est nécessaire d'octroyer un congé payé compensatoire.

\section{B - L'ÉQUIPEMENT ET LE MATÉRIEL NÉCESSAIRES AU TRAVAIL À DISTANCE}

En ce qui concerne la deuxième caractéristique du travail à distance, liée à l'équipement et au matériel nécessaires, l'employeur n'est pas nécessairement contraint de les mettre à disposition du salarié ou d'en assumer le coût. Cet aspect a été parfaitement compris au début du confinement dans la mesure où une grande partie de l'activité économique a brusquement été paralysée. Néanmoins l'état d'urgence sanitaire n'a cessé d'être prolongé depuis le mois de mars. Initialement, prévu pour 90 jours, jusqu'au 9 juin, le confinement a été prolongé jusqu'au 7 septembre, et de nouveau, jusqu'au 6 décembre, en raison du nombre élevé de personnes infectées et décédées. Entre-temps, la reprise progressive des activités au mois de mai a été organisée en quatre phases (le Pérou est actuellement en phase $n^{\circ} 3$ ).

Au mois de juillet, plus de 220000 travailleurs exerçaient leur activité professionnelle à distance, selon les informations des responsables du MTPE. II n'existe pas de statistiques sur le nombre d'employeurs ayant fourni les équipements nécessaires ou assumé leur coût. Toutefois, même si dans certains cas les travailleurs ont pu récupérer l'ordinateur portable qu'ils utilisaient sur leur lieu de travail, l'employeur n'a pas assumé les dépenses plus importantes engagées par le travailleur pour exercer son activité ou minimiser certains risques, comme les risques ergonomiques. Cette question mériterait d'être étudiée, afin de mieux protéger les intérêts des travailleurs, confrontés à une situation, au départ temporaire, qui s'éternise. 